\title{
Limitações à Extrafiscalidade Aplicáveis ao Fator Acidentário de Prevenção - FAP
}

\section{Daniel de Magalhães Pimenta}

Advogado. Mestre em Direito Empresarial pelas Faculdades Milton Campos - FMC, Nova Lima, MG, Brasil. Professor do curso de Pós-Graduação das Faculdades Promove. Integrante dos grupos de pesquisa Direito Empresarial na Contemporaneidade e Direito Tributário - Extrafiscalidade, coordenados pelos professores. Sacha Calmon Navarro Coelho e Valter de Souza Lobato, Faculdades Milton Campos - FMC, Nova Lima, MG, Brasil. daniel@sgarbimagalhaes.com.br

\begin{abstract}
Resumo
A determinação de um mecanismo como o FAP, que impõe alíquotas individuais majoradas da contribuição previdenciária a contribuintes que apresentam maiores índices de frequência de acidentes de trabalho e de concessão de benefícios previdenciários de ordem acidentária, desafia o intérprete a buscar suas conclusões nos pilares teóricos da extrafiscalidade, dada a enorme complexidade e riqueza do tema. 0 presente artigo procura analisar alguns aspectos atinentes à matéria, demonstrando de que forma os limites à extrafiscalidade podem interferir na sistemática instituída pelo poder tributante, e sob qual ótica o FAP, tal qual delimitado pelo legislador e pelas normativas reguladoras atuais sobre a matéria, pode representar riscos às garantias constitucionais definidas na ordem econômica e nas limitações ao poder de tributar.
\end{abstract}

Palavras-chave: FAP. Extrafiscalidade. Tributação. 


\title{
LIMITATIONS ON EXTRAFISCALITY FOR THE PREVENTION ACCIDENT FACTOR - FAP
}

\begin{abstract}
The determination of a mechanism such as FAP, which imposes higher individual tax rates of social security contributions to taxpayers who have higher numbers of labour accidents and granting of accident pension benefits, challenges the interpreter to pursue its conclusions on the theoretical pillars of extrafiscality, given the enormous complexity and theme of wealth. This study seeks to analyze certain aspects of the matter, demonstrating that limits on extrafiscality can interfere with the systematic implemented by the taxing power, and how FAP, like delimited by the legislature and by current regulatory norms on the matter, may impose risks to constitutional guarantees defined in the economic order and in the limitations on constitutional the power to tax.
\end{abstract}

Keywords: FAP. Extrafiscality. Taxation. Economy.

\section{Sumário}

1 Introdução: FAP e Suas Raízes Extrafiscais. 2 Limitações à Extrafiscalidade Segundo a Doutrina. 2.1 A classificação dos limites por Marciano Seabra de Godoi. 2.2 A classificação abrangente de Marcus de Freitas Gouvêa. 3 FAP em Face dos Limites Extrafiscais Definidos na Ordem Constitucional Econômica e Tributária. 3.1 Limites da ordem tributária relevantes. 3.2 Limites da ordem econômica e demais ramos relevantes. 4 Conclusões. 5 Referências. 


\section{INTRODUÇÃO: FAP e Suas Raízes Extrafiscais}

Analisando as raízes históricas do Fator Acidentário de Prevenção - FAP - constatamos que sua criação se deu em um contexto de desequilíbrio fiscal verificado no Brasil desde o final do século 20. Naquela ocasião o governo federal, preocupado com o aumento das despesas previdenciárias decorrentes de benefícios concedidos em função de acidentes de trabalho e de aposentadorias especiais, ${ }^{1}$ instituiu a contribuição para financiamento do Seguro Contra Acidentes de Trabalho (SAT), inserindo no ordenamento tributário nacional o artigo 22, II da lei 8.212/91, que passou a prever a cobrança de contribuição social para o financiamento dos benefícios previdenciários de risco definidos nos artigos 57 e 58 da lei 8.213/91 e daqueles concedidos em razão da incapacidade laborativa decorrente dos riscos ambientais do trabalho.

Além dessa importante inovação trazida a partir de 1998, que contemplava o custeio das despesas adicionais com esses benefícios especiais, o Executivo também procurou criar uma solução para a redução os gastos públicos realizados sob essa rubrica.

Efetivamente, o Executivo federal tentou buscar soluções não somente para os efeitos do aumento dos gastos públicos, por meio da instituição de uma fonte fiscal de custeio complementar, mas também para as causas dessas despesas, quais sejam, os riscos e condições de trabalho severas até então verificados no ambiente de trabalho das empresas.

O pensamento silogístico do Executivo era de que, com a redução dos acidentes de trabalho e dos riscos ambientais laborais, menor seria a incidência de benefícios previdenciários dessa natureza, gerando-se por consequência o desejado equilíbrio das contas públicas.

1 As aposentadorias especiais, segundo a lei 8213/91, são aquelas concedidas pelo desempenho de atividades sujeitas a riscos e condições de trabalho especialmente severas. 
Nesse contexto, surgiu no ano de 2002, em resposta à necessidade de redução de gastos previdenciários e do desenvolvimento das políticas públicas de proteção da saúde, higiene e segurança do trabalhador, a medida provisória $\mathrm{n}$. 83, de 12 de dezembro de 2002 , posteriormente convertida na lei federal 10.666 , de 8 de maio de 2003 , que pela primeira vez previu o mecanismo extrafiscal que pouco mais tarde seria intitulado Fator Acidentário de Prevenção (FAP).

Segundo o artigo $10^{\circ}$ da MP 83/2002, convertida posteriormente na Lei 10.666/2003, as alíquotas de 1\%, 2\% e 3\% da contribuição ao SAT poderão ser reduzidas em até $50 \%$ ou majoradas em até $100 \%$, dependendo do desempenho de cada empresa em relação ao grau de incidência de incapacidade laborativa decorrente dos riscos verificados em seu ambiente de trabalho.

Esse novo elemento trouxe profundas alterações na sistemática de apuração da contribuição ao SAT pois, além da majoração ou redução das alíquotas efetivas anteriormente existentes, instituiu-se a aplicação de alíquota específica e individual para cada contribuinte, e criou-se ainda sistemática de apuração complexa e que leva em consideração o ranking de empresas elaborado segundo metodologia específica definida em regulamento.

Outrossim, verificou-se a partir do artigo10 da lei 10.666/2003 a aplicação de uma evidente função extrafiscal da contribuição ao SAT, pois a União, por meio de Decreto Regulamentar posterior, elegeria um padrão de comportamento a ser alcançado pelas empresas em relação às melhorias das condições da saúde e de ambiente de trabalho, e ofereceria a elas um prêmio ou uma punição pelos resultados decorrentes dos investimentos nessa área, por meio da flexibilização das alíquotas básicas da contribuição de acordo com o desempenho da empresa em cálculos realizados mediante metodologia aprovada pelo Conselho Nacional de Previdência Social. 
A exposição de motivos da MP 83/2002 retrata claramente a intenção extrafiscal do governo federal com a adoção dessa nova metodologia. Vejamos:

32. A proposta visa introduzir mecanismos que estimulem os empresários a investirem em prevenção e melhoria das condições do ambiente de trabalho, mediante a redução, em até $50 \%$, ou acréscimo, em até $100 \%$, da alíquota de contribuição destinada ao financiamento das aposentadorias especiais ou dos benefícios concedidos em razão de acidentes ou de doenças ocupacionais, conforme a posição da empresa na classificação geral apurada em conformidade com os índices de frequiência, gravidade e custo das ocorrências de acidentes, medidas segundo metodologia aprovada pelo Conselho Nacional de Previdência Social - CNPS (Brasil, 2002).

Com efeito, mais do que simplesmente arrecadar fundos para o custeio da máquina previdenciária, a contribuição ao SAT passava a exercer papel fundamental no estímulo de investimentos em prevenção e melhoria das condições do ambiente de trabalho, à medida que quanto maior os investimentos, em tese menores seriam as alíquotas aplicáveis aos contribuintes.

A nova função extrafiscal da contribuição ao SAT era, então, inequívoca com a edição da MP 83/2002 e da lei 10.666/2003, mas pairava ainda no ordenamento dúvida sobre o formato a ser adotado pelo Executivo para cumprir com essa finalidade.

Visando a responder a esse questionamento, o Decreto 6.042/2007, alterado pelo Decreto 6.957/2009 e instruído por portarias e outros atos normativos, instituiu o que hoje se conhece como Fator Acidentário de Prevenção (FAP), que nada mais é do que um multiplicador que, aplicado à alíquota inicial do SAT (1\%, $2 \%$ ou $3 \%)$, gerará o valor da alíquota efetiva a ser recolhida mensalmente pelo contribuinte durante o exercício fiscal subsequente. 
Do ponto de vista meramente técnico-procedimental, o multiplicador que constitui o FAP seria então o resultado da aplicação da metodologia aprovada pelo Conselho Nacional de Previdência Social (CNPS) que, aplicado à alíquota básica definida pelos critérios de Riscos Ambientais do Trabalho (RAT), geraria a alíquota efetiva da contribuição ao SAT a ser recolhida pelo contribuinte.

Já do ponto de vista jurídico, que constitui o ponto de interesse do presente estudo, o FAP se revelaria como principal instrumento de aplicação da função indutora extrafiscal em relação à contribuição ao SAT.

Evidentemente, a norma contida no artigo $10^{\circ}$ da lei 10.666/2003 e regulamentada pelos decretos governamentais posteriores induz o contribuinte a comportamentos desejados pelo legislador.

A extrafiscalidade, entretanto, ainda que seja hoje elemento central do FAP, deve balizar-se sob os fundamentos próprios aplicáveis a esse tipo de norma. Com efeito, toda a teoria constitucional contemporânea baseia-se no reconhecimento de garantias fundamentais da sociedade ante $o$ poder regulamentador estatal, e não será diferente em relação às normas tributárias indutoras.

Dentro desse espectro é que se centra a presente pesquisa, pois, se não há dúvidas quanto à possibilidade de instituição de normas extrafiscais indutoras de comportamento tais como a prevista no Decreto 6.042/2007, é importante constatar se estas estão adequadas aos limites, tributários ou não, que percorrem o ordenamento constitucional pátrio.

Assim, o presente artigo penetra no estudo dos limites da extrafiscalidade para chegar a algumas das conclusões sobre a validade do FAP perante o ordenamento jurídico brasileiro. 
Para tanto serão abordadas as limitações ao poder extrafiscal demarcadas pela doutrina, e apresentados aspectos da ordem constitucional econômica e tributária que, aplicados ao FAP, podem gerar discussões sobre a compatibilidade dessa sistemática no ordenamento brasileiro.

\section{LIMITAÇÕES À EXTRAFISCALIDADE SEGUNDO A DOUTRINA}

Iniciando as discussões propostas, importante revela-se adotar uma definição de extrafiscalidade em Direito Tributário que melhor se adapte aos objetivos do presente estudo, posto que a doutrina revela conceitos e definições distintas para os mais diversos fins e extensões.

Isso posto, definimos a extrafiscalidade como o fenômeno jurídico no qual o Estado, por meio da imposição de uma obrigação tributária, procura realizar finalidade constitucional diversa da mera arrecadação para o custeio de suas atividades.

Apurada a definição de extrafiscalidade a ser utilizada no presente ensaio, passemos a demonstrar os limites teóricos e práticos para a imposição desse fenômeno no Estado brasileiro, segundo a doutrina pátria mais abalizada sobre o tema.

\subsection{A classificação dos limites por Marciano Seabra de Godoi}

A maioria dos doutrinadores aborda os limites da prática extrafiscal com base nos dispositivos constitucionais que a fundamentam. Para esses autores a norma extrafiscal, além da necessária vinculação aos 
fundamentos aplicáveis ao Direito Tributário brasileiro, também deverá atender às determinações constitucionais relativas à finalidade pela qual foi aplicada. ${ }^{2}$

Nesse norte, muito válidas para a definição das limitações constitucionais da extrafiscalidade são as digressões promovidas por Godoi (2004) sobre o tema. Para este autor, a norma extrafiscal não poderá ser realizada se violar pelo menos um dos limites a seguir:

- Aqueles relacionados aos direitos fundamentais

- Aqueles relacionados a direitos de propriedade

- Aqueles relacionados ao dever de contribuir com os gastos públicos

- Aqueles relacionados à competência tributária material e legislativa

- Aqueles relacionados à capacidade contributiva

\section{Limites relacionados aos direitos fundamentais}

A limitação da extrafiscalidade pelos direitos fundamentais impõe o respeito, pelo legislador extrafiscal, àquela série de direitos individuais e sociais dispostos explícita e implicitamente na Constituição de 1988. Assim, não seria possível a instituição de uma medida extrafiscal como uma taxa judiciária por demais majorada que limitasse, por exemplo, o acesso das pessoas à Justiça.

2 Schoueri, ao delimitar os limites das normas tributárias indutoras, estabelece a necessária revisão das limitações constitucionais ao poder de tributar juntamente com os princípios que norteiam a ordem econômica nacional, uma vez que, se a extrafiscalidade se manifesta por meio de uma intervenção do Estado no domínio econômico, os pressupostos econômicos definidos na Constituição deverão ser obedecidos (Schoueri, 2005). 


\section{Limites relacionados a direitos de propriedade}

Da mesma forma, outro limite à extrafiscalidade, para o autor mineiro, seriam os direitos de propriedade, e nesse ponto não se estaria diante somente dos princípios da vedação ao confisco, mas também daqueles relativos ao exercício dos direitos sobre a propriedade, sendo vedada, portanto, qualquer medida de objetivo extrafiscal que limitasse o exercício desse direito, e nesse ponto se incluiria inclusive a vedação ao exercício da livre-iniciativa, também referido no presente estudo.

\section{Limites relacionados ao dever de contribuir com os gastos públicos}

No que tange ao dever fundamental de pagar impostos e contribuir com os gastos públicos, tão celebremente festejado por Nabais, ${ }^{3}$ o professor Marciano Seabra Godoi chama a atenção para a dimensão material do tributo, demonstrando a impossibilidade de medida tributária extrafiscal em situações em que não houver a representação de riqueza, pois o tributo não pode ser dissociado da fiscalidade e do conceito de tributo, conforme já delineado nos tópicos anteriores.

\section{Limites relacionados à competência tributária material e legislativa}

Sobre os limites relacionados à competência tributária, o professor mineiro repete a lógica de que somente o ente dotado de capacidade tributária pode realizar medidas extrafiscais relativas a tributos de sua competência. Isso impede, por consequência, a realização do famoso provérbio “fazer cortesia com o chapéu alheio", sob pena de usurpação da competência constitucionalmente definida.

Importante ainda nesse diapasão rever lição de Schoueri (2005) que, interpretando o posicionamento de vários doutrinadores respeitados em nosso ordenamento, entre eles Ataliba e Ruy Barbosa Nogueira,

3 Nabais, 1988. 
reconhece a necessidade de observância cumulativa das competências tributária e material para a edição de normas extrafiscais de natureza indutora. Vejamos:

Para a solução da questão, importa que se reafirme, neste passo, que as normas tributárias indutoras são reflexo do poder de regular, não do poder de tributar. Não obstante se insiram no ordenamento por meio de tributos que lhes servem de veículos, são elas instrumentos de que se vale o legislador para conduzir, por indução, o comportamento dos contribuintes, gerando estímulos positivos e negativos, conforme o contribuinte incorra, ou não, na hipótese prevista em lei. Ora, se a competência legislativa está regulada pelos artigos 22 e ss. da Constituição Federal e sendo as normas tributárias indutoras forma de legislação sobre aquelas matérias, conclui-se estarem elas sujeitas àqueles preceitos constitucionais.

Assim é que as normas tributárias indutoras sujeitam-se: I) por força do veículo pelo qual se introduzem no mundo jurídico, às regras de repartição de competências tributárias; II) por força da matéria que regulam, às regras de competência legislativa. Conclui-se, portanto, pela necessária concomitância de competências, para que se introduzam normas tributárias indutoras válidas no ordenamento brasileiro (Schoueri, 2005, p. 251).

\section{Limites relacionados à capacidade contributiva}

Por fim, ligando a extrafiscalidade à ideia de justiça fiscal, sempre presente no capítulo tributário da Carta Constitucional brasileira, o professor Godoi repele a existência de medidas com objetivos extrafiscais que, por sua natureza, não contemplem a capacidade contributiva econômica, no que é seguido por grandes expoentes da literatura jurídica, como o professor Schoueri, que, em sua já clássica obra sobre as normas indutoras tributárias, trata da capacidade contributiva como um norte a ser respeitado na instituição daquelas normas. 
Nabais (1988), por seu turno, sustenta que os limites da extrafiscalidade repousam em princípios gerais de Direito Tributário e Administrativo, tais como a proibição de excesso, a proporcionalidade e a igualdade, bem como devem ser adequados e mais necessários para a realização dos objetivos para os quais foram instituídos do que outras medidas extrafiscais de caráter não tributário, tais como as subvenções.

Assim, segundo a doutrina, a prática extrafiscal deverá respeitar, no plano constitucional, os princípios limitadores do poder de tributar, que poderiam inclusive, em alguns casos excepcionais, ser mitigados, mas não desrespeitados. ${ }^{4}$ Da mesma forma, tendo em vista que as normas tributárias extrafiscais revelam tentativa de regulação da atividade econômica, os princípios aplicáveis à ordem econômica deverão também ser observados, inclusive a livre-iniciativa, a busca pelo pleno emprego, o desenvolvimento do mercado nacional e a redução das desigualdades regionais.

Interessante, nesse ponto, é verificar que tais princípios não tributários aplicam-se tanto como mola propulsora da extrafiscalidade quanto como limitadores de sua aplicação. Com efeito, por vezes uma determinada medida tributária poderá ser utilizada com a finalidade de fomentar a melhoria das condições do ambiente de trabalho - caso do Fator Acidentário de Prevenção - FAP, instituído pela lei 10.666/2003 - porém não poderá violar a livre-iniciativa, punindo o contribuinte pelo risco normal da realização de uma atividade lícita.

À evidência, esse aspecto jurídico normativo de controle das normas tributárias extrafiscais é essencial para enxergar os limites da atuação do Estado.

${ }_{4}$ Caso, por exemplo, da mitigação do princípio da legalidade estrita na instituição de tributos de natureza extrafiscal, que se observou válida no julgamento do RE 343.446/RS, no qual o Supremo Tribunal Federal julgou que os critérios definidores básicos do RAT, que distingue as alíquotas aplicáveis à contribuição ao SAT, poderiam ser criados por meio de decreto, se a lei estipulasse um mínimo teórico para isso. 


\subsection{A classificação abrangente de Marcus de Freitas Gouvêa}

Digna de nota é também a abrangente classificação trazida pelo pesquisador Marcus de Freitas Gouvêa (2006), que reconhece não somente limites jurídicos internos à instituição da extrafiscalidade, mas também forças econômicas e sociais que exercem papel significativo na tomada de medidas extrafiscais.

A classificação proposta pelo referido autor aponta para a existência de quatro grandes limites à aplicação da extrafiscalidade na contemporaneidade, quais sejam: os limites jurídico-principiológicos, os limites jurídico-normativos, os limites lógicos e os limites socioeconômicos.

\section{Limites jurídico-principiológicos}

Por limites jurídico-principiológicos o autor sustenta que a extrafiscalidade, enquanto princípio epistemológico da ciência do Direito e ontológico, da Tributação, deve seguir os princípios que a fundamentam, mais especificamente os princípios informadores do Direito Tributário e que limitam o poder de tributar, e aqueles que orientam a atividade econômica, social e cultural do Estado, que se deseja valorizar por meio da medida extrafiscal. Defende o autor:

Com isso, seja qual for o instrumento utilizado pelas ações tributárias (apesar das peculiaridades quanto às regras) não poderá desrespeitar os princípios de Direito Tributário, assim como a capacidade contributiva, o princípio da não-surpresa, o princípio da legalidade tributária (que não tem a mesma conotação no Direito Econômico) e o princípio do não-confisco. 
Em linhas gerais, quanto aos princípios que guardam valores constitucionais não tributários, é lícito dizer que devem ser observados pela tributação extrafiscal, pois esta não pode almejar finalidade vedada pela Carta ou contrária a seus ditames, mesmo que o proibitivo seja implícito (Gouvêa, 2006. p. 254-255).

Com razão o autor, pois, a nosso ver, a visão restritiva de Nabais (1988) sobre a aplicação dos princípios do Direito Tributário à extrafiscalidade não encontra guarida no Direito brasileiro, à medida que a norma extrafiscal sempre preserva sua natureza tributária, não podendo ser afastada a observância dos caracteres próprios desse ramo do Direito. Da mesma forma, entendemos que a norma extrafiscal deve acompanhar os princípios e diretrizes constitucionais relacionados à finalidade extrafiscal que a fundamenta, não podendo haver norma extrafiscal que vise ao objetivo não compreendido na Constituição.

Importante ainda ressaltar a visão abrangente do autor ao delimitar que, entre os princípios não tributários a serem seguidos pela norma extrafiscal, devem ser respeitados não somente os princípios da ordem econômica, como disposto por parte da doutrina, mas também todas as diretrizes políticas e sociais que permeiam o objetivo extrafiscal, devendo haver a necessária ponderação de princípios quando houver dois ou mais princípios que possam, no caso concreto, ser antagônicos ou conflitantes.

\section{Limites jurídico-normativos}

Se existem limites principiológicos, consequentemente haverá também limites jurídico-normativos da extrafiscalidade, representados, na visão de Gouvêa, por regras jurídicas que impedem de modo objetivo a aplicação da extrafiscalidade.

Chama a atenção o referido autor que, por se tratar de princípio, a extrafiscalidade apenas sofre limitações igualmente principiológicas. Os tributos e demais instrumentos de aplicação da extrafiscalidade entretanto, 
estão sujeitos aos limites das regras jurídicas. Nesses casos, apesar de uma principiologia adequada, pode haver vedação expressa pelo ordenamento jurídico.

Sendo assim, se houver alguma regra objetiva ou relativa que impeça a adoção da extrafiscalidade em casos específicos, logicamente esse fenômeno não poderá ser realizado pelo ente tributante.

Nesse campo de limites são identificadas quatro situações em que regras jurídicas poderiam impossibilitar a edição de efeitos extrafiscais à norma tributária: a) os limites objetivos relativos, que se verificam quando uma norma proíba a utilização de determinado expediente tributário para realizar um valor específico; b) os limites objetivos absolutos, representados por normas que não proíbam a extrafiscalidade, mas sim a instituição de determinado tributo ou medida tributária; c) os limites subjetivos, que são relacionados a situações em que o ente tributante não detém competência tributária para instituir a medida extrafiscal e d) os limites normativos formais, que se revelam pela imposição do meio legal adequado para se determinar a medida extrafiscal.

Em todas as situações expostas, a extrafiscalidade, ainda que adequada principiologicamente, poderia ser vedada por regras jurídicas, justificando, pois, a classificação adotada.

\section{Limites lógicos}

O professor Marcus Gouvêa aponta ainda para o caso de situações em que, apesar da existência de principiologia e normas que permitam a instituição de medida extrafiscal, esta não se concretiza por razões lógicas, decorrentes da imprestabilidade da medida para a efetivação do objetivo extrafiscal.

Entre os exemplos citados pelo autor em sua obra, aquele que nos parece mais aceitável para demonstrar a existência de um limite lógico é a imprestabilidade da adoção de medidas extrafiscais em tributos indiretos 
incidentes sobre o consumo, como tentativa de melhorar a distribuição de renda e de riqueza e na repartição do custeio das atividades estatais. Tendo em vista que os referidos tributos afetam somente preços relativos, a prática demonstra que a instituição de eventuais medidas extrafiscais não terá poder de realizar os fins supostamente pretendidos pelo ente tributante.

Para evitar a usurpação de limites lógicos, adverte Gouvêa que "há de se verificar a natureza dos institutos jurídicos, porquanto, por razões lógicas, alguns são capazes de promover determinadas conseqüências e incapazes de promover outras, variando, assim, os efeitos extrafiscais decorrentes de cada um destes institutos” (Gouvêa, 2006, p. 263)

Em outras palavras, é necessário que se observe, para a instituição de medidas extrafiscais, critérios de eficácia do instituto a ser adotado, sob pena de não se promover a finalidade adjacente desejada pelo Estado.

\section{Limites socioeconômicos}

Talvez a maior contribuição de Gouvêa ao presente estudo esteja no reconhecimento das forças externas ao Direito como limitadoras da atividade extrafiscal do Estado.

De toda a construção histórica trazida nessa parte de sua obra, extrai-se a importante consideração de que "a extrafiscalidade respeita as forças do mercado e reconhece que, excepcionalmente, as ações tributárias podem ficar destituídas de efeito, seja por má elaboração ou por implementação inadequada” (Gouvêa, 2006, p. 263).

E não somente os agentes e elementos econômicos interfeririam na instituição de medidas extrafiscais. Também medidas social ou politicamente indesejadas podem funcionar como limitadoras da atividade extrafiscal do Estado. 
Sendo assim, arremata o autor, a nosso ver com peculiar brilhantismo, que a extrafiscalidade permitida pelo ordenamento e principiologicamente admitida pode ser inviabilizada pelo mercado e pela realidade social.

Efetivamente, alguns instrumentos tributários extrafiscais, apesar de juridicamente legítimos, tendem a ser repelidos pelos destinatários da norma extrafiscal - agentes econômicos, contribuintes e sociedade - se se revelarem contrários à realidade social e econômica que se desenha em determinado momento histórico. Não se trata, aqui, de primazia da ordem econômica sobre a jurídica, tese há muito superada pela doutrina e pela jurisprudência. Na verdade, trata-se de reconhecer que estes elementos acabam por interferir tanto na adoção quanto na eficácia de medidas extrafiscais, afinal de contas o Direito não deve ser amorfo e desconhecer os elementos e a realidade que 0 circundam.

Utilizando a teoria sistêmica explicada por Lobato (2010), os limites antes dispostos seriam identificados como elementos que se encontram no entorno do sistema jurídico, e que são observados de dentro do sistema (hetero-observação) para a construção das normas a partir de suas referências próprias (autopoiese), e que serão destinadas a cumprir a função do sistema. Em outras palavras, o sistema jurídico, fechado enquanto sistema, não se submete ou se confunde com os caracteres dos sistemas econômicos e sociais, mas observa-os por meio de sua necessária abertura cognitiva, para processar e assimilar internamente essas informações externas e criar condições de cumprir sua função própria, pela geração das normas convenientes e permitidas pelo sistema.

O reconhecimento das forças sociais e econômicas como possíveis interferências da atividade extrafiscal é de relevante importância, pois abre a possibilidade do contínuo desenvolvimento dinâmico da extrafiscalidade enquanto fenômeno jurídico que sempre existirá nos sistemas jurídicos contemporâneos. 


\section{Conclusões sobre a seção}

Concluindo a presente seção, apresentam-se então classificações que, apesar de distintas em relação à amplitude dos limites da extrafiscalidade, apresentam convergências quanto à necessidade de observância cumulativa das normas, princípios e regras aplicáveis ao ordenamento constitucional tributário e à ordem constitucional aos quais se liga a finalidade extrafiscal da norma indutora.

O núcleo duro da norma extrafiscal será, portanto, compreendido pelas diretrizes constitucionais próprias que regem a instituição e cobrança de tributos, acrescidas, de forma inseparável, dos fundamentos ligados ao objetivo constitucional extratributário para o qual o tributo foi instituído, conforme já alertava lição de Moschetti (1980).

Especificamente em relação ao FAP, tendo em vista que segundo o próprio legislador o referido instituto visa a estimular investimentos em prevenção e melhoria das condições do ambiente de trabalho dentro do ambiente corporativo, resta claro que o ramo constitucional cujos princípios e normas constitucionais devem ser analisados em integração com o arcabouço tributário nacional será o da ordem econômica. Nesse sentido, além de o artigo 170 caput da Constituição da República Federativa do Brasil de 1988 (CF/88) definir a valorização do trabalho humano como fundamento da ordem econômica brasileira, a busca da realização dos princípios da função social da propriedade, da busca do pleno emprego e da redução das desigualdades sociais, definidos nos incisos do mesmo dispositivo, são a nosso ver o combustível constitucional que moveu a máquina tributária do Estado para a instituição da metodologia FAP.

Definidos os marcos normativos a serem utilizados na análise dos limites à extrafiscalidade, fica agora menos árdua a tarefa de identificar como o FAP seria afetado por tais limitações. 


\section{FAP EM FACE DOS LIMITES EXTRAFISCAIS DEFINIDOS NA ORDEM CONSTITUCIONAL ECONÔMICA E TRIBUTÁRIA}

Iniciando o principal tópico do presente estudo, ressaltamos que nosso interesse foi o de trazer novas perspectivas relativas a alguns elementos do FAP que, a nosso ver, constituem discussões atuais vinculadas à extrafiscalidade. Dessa forma, não foi possível, até pela limitação de espaço, abordar todos os aspectos jurídicos que são apresentados pela doutrina e jurisprudência pátrias. Nosso objetivo, como acima disposto, foi focar nos aspectos da limitação da atividade estatal, e, dentro desse espetro, apontar novos caminhos para enriquecer a discussão dobre o tema.

\subsection{Limites da ordem tributária relevantes}

\section{Legalidade}

Como disposto no tópico anterior, a instituição de tributos de caráter extrafiscal deverá observar as limitações do poder de tributar que se relacionem à garantia dos direitos fundamentais previstos na Carta Constitucional, tendo em vista configurarem aqueles como normas tributárias por natureza.

Entre esses direitos, a proibição de ofensa à legalidade tributária foi historicamente um dos primeiros temas abordados em relação ao FAP. Argumenta parte da doutrina, baseada nas regras de competência tributária legislativa, que a definição dos elementos centrais da contribuição ao SAT pelo FAP, dentre eles as alíquotas efetivas e critérios de apuração e mensuração do tributo, não poderia ser realizada por meio de decreto, sob pena de usurpação da competência formal do Legislativo prevista no artigo 146, II c/c artigo 150, I da CF/88. Não se trataria, pois, de um vício material, mas sim formal da norma extrafiscal. 
No mesmo ínterim, argumenta-se que a norma constitucional permissiva do FAP em sua atual redação, qual seja, o $§ 9^{\circ}$ do artigo 195 da $\mathrm{CF} / 88$ alterado pela EC $47 / 2005$, foi promulgada posteriormente ao artigo 10 da lei 10.666/2003, não podendo a União pretender conceder constitucionalidade superveniente a essa legislação.

Para essa parte da doutrina, como o atual FAP regulamentado pelo Decreto 6.042/2007 e normas posteriores preveem o porte da empresa e a condição estrutural do mercado de trabalho como critérios de definição da alíquota efetiva, esses critérios já deveriam estar previsto na legislação tributária de regência.

Ocorre que, apesar de essa possibilidade estar prevista na emenda constitucional 47/2005, que alterou a redação do $§ 9^{\circ}$ do artigo 195 da $\mathrm{CF} / 88$, a legislação que instituiu a sistemática do FAP, qual seja, o artigo 10.666/2003, foi editada antes da promulgação da referida emenda constitucional, não se podendo aplicar validade retroativa à norma de 2003, quando não havia a previsão de diferenciação de alíquotas pelo porte das empresas e condição estrutural do mercado de trabalho.

Bem, para a solução das questões expostas, os tribunais brasileiros, sobretudo o Supremo Tribunal Federal, ainda não se posicionaram definitivamente em relação aos critérios definidos ao FAP. A maioria dos julgados produzidos a partir de 2010, entretanto, data de início da vigência efetiva da metodologia que gera o FAP, aponta para a possibilidade de instituição de critérios técnicos de aplicação da norma tributária por meio de decreto, especificamente a alteração dos critérios de definição do RAT. Para tanto, baseiam-se em precedente do STF, que na suposta esteira da mais atual doutrina sobre a matéria, reconhece que a legalidade definida no sistema tributário brasileiro admite a fixação de aspectos da norma que possam ser definidos pelo intérprete, no caso o ente tributante, mediante atos normativos. 
Segundo a doutrina adotada pelo Supremo, desde que a interpretação esteja dentro dos limites do tipo definido pela legislação, não há impossibilidade da definição de critérios e aspectos da norma tributária pela norma infralegal, posto que ao legislador não é dado esmiuçar todas as hipóteses possíveis de incidência da norma tributária, como acreditavam os defensores das teorias que defendem a "tipicidade cerrada" ou os conceitos fechados e imutáveis dentro do Direito Tributário.

Como se pode verificar no bojo do voto condutor do referido precedente jurisprudencial emitido pelo Supremo Tribunal Federal, ${ }^{5}$ o constituinte, ao determinar ao poder público a necessidade de observância ao princípio da legalidade na instituição de tributos, define que os elementos centrais dos tributos devem ser fixados em lei, citando nobre lição do saudoso professor Geraldo Ataliba.

Em certos casos, entretanto - dispõe o relator -, a aplicação da lei, no caso concreto, exige a aferição de dados e elementos. Nesses casos, a lei, fixando parâmetros e padrões, comete ao regulamento essa aferição. Não há falar, em casos assim, em delegação pura, que é ofensiva ao princípio da legalidade genérica (C. F, artigo $5^{\circ}$, II) e da legalidade tributária (C. F., artigo 150, I) (Brasil, Supremo Tribunal Federal - STF. 2003b).

Ao assim dispor, o julgador admite a existência de tipos e conceitos indeterminados em Direito Tributário, que podem exigir a complementação de sua extensão por meio de atos interpretativos, tais como os decretos normativos.

Por essa necessária abertura, que acompanha a evolução da própria doutrina acerca da legalidade tributária, entende o Supremo Tribunal Federal que as alterações promovidas por meio de decreto, desde que

${ }_{5}$ Brasil. Supremo Tribunal Federal - STF, 2003b. 
estejam dentro do escopo definido pelo legislador e sejam advindos de uma delegação derivada, não usurpam a legalidade tributária definida na Constituição.

Sendo assim, o referido tema central que atualmente vem sendo discutido nos tribunais, e que se remete à possibilidade de regulamentação do FAP por meio de Decreto Legislativo, em princípio deverá ter o mesmo deslinde da discussão posta no precedente definido pelo Supremo, uma vez que, além de terem fundamentos semelhantes, seguem a linha contemporânea acerca da observância do princípio da legalidade em matéria tributária.

No que respeita aos demais aspectos da legalidade que ainda não foram objeto de detida análise pelos tribunais, porém, ainda não houve qualquer definição por parte da jurisprudência pátria, até porque poucos são os julgados que chegam a abordar a constitucionalidade superveniente enquanto tese. Advoga, entretanto, em favor dos defensores dessas teses, precedente do Supremo Tribunal Federal, ${ }^{6}$ que em caso semelhante referente ao alargamento da base de cálculo do PIS e da Cofins, definiu que a edição da EC 20/98 não concedeu constitucionalidade superveniente às leis $9.715 / 98$ e $9.718 / 98$, que por conta disso foram declaradas inconstitucionais.

No caso do FAP, a redação anterior do $\$ 9^{\circ}$ do artigo 195 da CF/88 permitia somente a flutuação das alíquotas e bases de cálculo em razão da atividade econômica e a utilização intensiva da mão de obra, que configuravam exatamente o escopo do RAT. Para viabilizar o FAP tal como disposto na lei 10.666/2003, que prevê alíquota específica em razão da posição da empresa dentro de seu setor econômico (condição estrutural do mercado de trabalho), era necessário algo mais, contudo esse acréscimo somente

${ }^{6}$ Nesse sentido, recomenda-se a leitura do acórdão $346.084 / \mathrm{PR}$, de relatoria do ministro Ilmar Galvão (Brasil. Supremo Tribunal Federal - STF, 2005b) 
foi integrado ao ordenamento em 2005. Ainda que o FAP tenha ficado no âmbito de estudos técnicos durante anos, tendo sido regulamentado por meio de decreto somente em 2007, seria necessária legislação atual, posterior à Emenda Constitucional 47/2005, para instituí-lo de acordo com o novo arcabouço trazido pelo constituinte derivado. Até a presente data, entretanto, não há notícia da existência de legislação formal posterior que convalidasse o modelo constitucional posterior a 2005, podendo efetivamente haver uma inconstitucionalidade que, segundo o Supremo Tribunal Federal, não pode ser sanada por uma interpretação integrativa entre a lei 10.666/2003 e a EC 47/2005, posto que a competência tributária legislativa positiva exige prévio poder de tributar ao ente público (artigo 150, I da CF/88).

Assim, acreditamos que os próximos capítulos dessa discussão podem reservar um novo panorama que represente efetiva proteção aos direitos do contribuinte, cabendo, logicamente, uma análise mais detida da matéria por parte do Judiciário para que se possa ultrapassar as ainda rasas discussões que hoje são travadas nos tribunais de revisão.

\section{Competência tributária material, isonomia, universalidade e capacidade contributiva}

Outra limitação constitucional à extrafiscalidade que pode ser visualizada na discussão relativa ao FAP revela-se na medida em que as normas tributárias indutoras devem guardar relação com a isonomia e a competência tributária material para definição da hipótese de incidência do tributo extrafiscal.

Nesse sentido, quando o constituinte outorga competência positiva para a instituição de tributo extrafiscal, chegamos ao limite jurídico-normativo positivo apontado pela doutrina de Gouvêa, mais especificamente os limites subjetivos, que dizem respeito a situações em que o ente tributante não detém competência tributária para instituir a medida extrafiscal, e os limites normativos formais, que se revelam pela imposição do meio 
legal adequado para se determinar a medida extrafiscal. Mais clara ainda é a lição de Godoi (2004), para quem a extrafiscalidade não pode estar presente quando houver limitações relacionadas à competência material tributária.

Ou seja, a competência tributária material positiva revela um dever negativo que impede a instituição do referente tributo em critérios distintos daqueles definidos no imperativo constitucional. E infelizmente é isso o que parece ocorrer em relação ao FAP, posto que os critérios materiais parecem ter sido extrapolados pelo Executivo.

Nesse passo, o já citado $\$ 9^{\circ}$ do artigo 195, I da CF/88 define a competência tributária positiva do legislador para instituição das bases de cálculo e tarifas diferenciadas, vedando, por interpretação exclusiva, qualquer outro critério de diferenciação não previsto na Carta Constitucional. Tais critérios materiais de definição das bases de cálculo, como se viu, são: a) a atividade econômica; b) a utilização intensiva de mão de obra; c) o porte da empresa e d) a condição estrutural do mercado de trabalho.

Note-se que, na realização deste imperativo constitucional, o legislador da contribuição ao SAT, já qualificado pela lei 10.666/2003 e atos normativos próprios emitidos pelo Executivo, estabelece os seguintes critérios de diferenciação de alíquota: a) atividade econômica (critério definidor do RAT); b) utilização intensiva da mão de obra (critério definidor do RAT); c) porte da empresa (critério definidor do FAP, presentes nos índices de massa salarial e número de vínculos definidos no Decreto 6.042/2007 e seguintes); d) condição estrutural do mercado de trabalho (critério definidor do RAT, que é diferenciado pela Classificação Nacional de Atividades Econômicas - CNAE - do setor econômico) e e) condição individual da empresa dentro do setor (critério definidor do FAP). 
Vê-se que entre os critérios apontados, resta aquele que leva exatamente a uma alíquota mais do que diferenciada e na verdade individualizada para cada contribuinte, qual seja, a situação da empresa dentro do seu setor.

Ora, pela limitação de competência material negativa anteriormente citada, o legislador não poderia lançar mão do critério relativo à condição individual da empresa dentro do setor. E nem poderia, pois a instituição de alíquotas individualíssimas como as propostas pelo FAP levam necessariamente a uma discussão da aplicação integrada de outros dois sobreprincípios da ordem tributária constitucional, quais sejam, a universalidade e a isonomia.

O constituinte sabiamente deixou de conceder expressa competência ao legislador para a instituição de tributo que levasse em consideração características personalíssimas de cada contribuinte, posto que tal atividade, ainda que desejada do ponto de vista da ordem econômica, violaria as garantias fundamentais à universalidade, à capacidade contributiva e à isonomia tributária.

Ora, quais seriam os pressupostos de ausência de isonomia que pudessem justificar alíquotas díspares para cada contribuinte inserido no ordenamento tributário nacional? No caso do FAP, esses critérios remontam ao número de acidentes de trabalho e o valor dos benefícios concedidos em razão desses eventos? Isso posto, qual a relação guardada nesses critérios que possa gerar uma objetiva situação em que não há isonomia, permitindo a diferenciação de alíquotas? Da mesma forma, existe nesses critérios distinção da capacidade econômica dos contribuintes que pudesse gerar tratamento tributário diferenciado? Por fim, se várias empresas não apresentam os critérios necessários para a aplicação do FAP, onde estaria presente a universalidade material que deve guardar relação com todas as normas tributárias? 
Para todas essas perguntas a resposta encontrada até o momento não é satisfatória, pois se a competência material negativa impedia a utilização de outros critérios justamente para evitar a violação dos princípios tributários supracitados, a nosso ver a União, ao propor e fazer aprovar um critério inovador, acabou por violar garantias constitucionais do contribuinte, e que advêm da própria relação desproporcional de forças entre o cidadão e o fisco.

Como há muito disposto pela doutrina, o desequilíbrio claro entre Estado e cidadão nas relações realizadas no ambiente constitucional faz com que sejam reiterados os mecanismos que possam coloca-los em situação de igualdade, ainda que formalmente. Justamente por esse motivo são ressaltadas as garantias individuais fundamentais, e que no Direito Tributário revelam-se pelas limitações constitucionais ao poder de tributar.

Ao defender a utilização de critério não previsto na Constituição, o Estado recorre ao seu poderio coercitivo e legitimação pela autoridade para impor ao contribuinte, data vênia de forma indevida, uma exação que, segundo o constituinte, não deveria existir justamente para evitar essa sobreposição estatal perante o indivíduo.

A legalidade estrita, aclamada por todos os defensores do Estado de Direito, demanda o respeito absoluto à ficção jurídica das garantias individuais fundamentais, justamente para reafirmar o pacto que legitima a existência do próprio Estado.

Ora, se a competência para instituição dos critérios aqui discutidos visa justamente a afirmar a isonomia, mediante a aplicação de alíquotas diferenciadas a contribuintes que se encontrem em situações jurídicas distintas, evidentemente as condições individuais do ambiente de trabalho representam violação do princípio tributário que justifica essa diferenciação determinada pela sistemática do FAP. 
A esta discussão podemos ainda agregar uma possível violação ao princípio da capacidade contributiva, pois se esta deve representar a exata medida da tributação, não se verifica como critério de distinção adequado o número de acidentes de trabalho e os investimentos realizados pelo empresário. Evidentemente, este critério de distinção não se liga à capacidade contributiva do contribuinte, não constituindo, a nosso ver, critério passível para distinção de alíquotas e base de cálculo de tributos.

Dessa forma, se o tributo deve incidir na medida da representação de riqueza observada e tomada pelo legislador como critério de distinção, onde estaria resguardada a capacidade contributiva em um critério que leva em consideração somente eventos tratados como ilícitos e que não representam qualquer representação de riqueza? À evidencia, esta é a nosso ver uma falha a ser corrigida na metodologia FAP, que estabelece critérios não condizentes com algumas das diretrizes aplicáveis ao ordenamento constitucional vigente.

Sendo assim, pelas limitações da ordem tributária anteriormente citadas, verificam-se possíveis inconstitucionalidades no modelo imposto de forma unilateral pelo ente tributante, constituindo dever da academia aprofundar-se no tema para determinar a revisão dos princípios para afastar as irregularidades da norma extrafiscal que, em nossa visão, acha-se em contraponto com o sistema tributário nacional.

\section{A aplicação dos limites objetivos absolutos da extrafiscalidade ao FAP}

Voltando à doutrina de Gouvêa (2006), dentro das fronteiras jurídico-normativas da extrafiscalidade encontram-se os limites objetivos absolutos, representados por normas que não proíbem a extrafiscalidade, mas sim a instituição de determinado tributo ou medida tributária. 
Analisando o FAP sob esse prisma, constatamos a existência de outra possível discussão que, inclusive, abrirá também o tópico a seguir, relativo à aplicação de limitações constitucionais da ordem econômica para a instituição da medida extrafiscal do FAP.

Nesse passo, apesar de o constituinte expressamente permitir a extrafiscalidade nas contribuições sociais definidas no inciso I do artigo 195 da CF/88, delimitando a competência material desse ato extrafiscal, fica claro, conforme já referido ao longo de todo o presente ensaio, que os caracteres da norma extrafiscal que aplica o desiderato do contribuinte não poderá violar o núcleo duro aplicável aos tributos, representado pelas normas e regras que delimitam a atividade fiscal do ente tributante.

Entre tais normas, a observância do conceito de tributo é de vital importância para a existência do fenômeno extrafiscal no Direito Tributário, posto que a natureza da norma tributária indutora, principalmente quando se reportar a critérios definidores de bases de cálculo e alíquotas, será evidentemente tributária.

Tendo esse entendimento como premissa maior, todos os caracteres do conceito de tributo deverão ser mantidos e observados na norma fiscal, entre eles a ausência de utilização do instrumento tributário como sanção decorrente de ato ilícito. Sem a configuração desses critérios, não deverá haver norma extrafiscal, ainda que a extrafiscalidade material seja permitida.

Trazendo a assertiva antes disposta à realidade do FAP, a atribuição de alíquotas diferenciadas de acordo com os investimentos em saúde e segurança do trabalho evidentemente possui a nobre função extrafiscal de promover a valorização do trabalho enquanto fundamento da ordem econômica constitucional. 
Ao instituir a extrafiscalidade por meio de regras e critérios que acabam por penalizar o contribuinte pela ocorrência de ilícitos, contudo, e não se diga que os acidentes de trabalho não são ilícitos trabalhistas, posto que se assim não fossem não gerariam indenizações nas demais esferas do Direito, evidentemente se estaria promovendo uma norma tributária inconstitucional para a realização de um fim constitucional, o que é há muito vedado por nosso ordenamento.

Os fins não justificam os meios escolhidos pela administração, e nesse sentido a nobreza do ato extrafiscal não se sustenta, por si só, sem os caracteres tributários que são utilizados como meio para a sua consecução. Concordando com esse entendimento, a - pesquisadora Martha Toríbio Leão, defende que as normas tributárias indutoras somente serão viáveis na medida em que não imponham ao contribuinte uma sanção pela prática do ato lícito que não é querido pelo Estado (Leão, 2014, p. 16).

Além de ser vedada a determinação de um ato ilícito como hipótese de incidência tributária, pelo conceito legal de tributo também é vedada distinção do valor do tributo diante da ocorrência de fatos caracterizados como ilícitos. Seria o mesmo que instituir uma alíquota adicional de contribuição social, incidente sobre a receita, contra empresas que fossem comprovadamente condenadas pelo crime de lavagem de dinheiro.

No caso hipotético exposto, apesar de o fato gerador e a hipótese de incidência não terem correlação com o ilícito, o agravamento da obrigação tributária, que passaria a constituir sanção indireta, seria evidentemente contrário às diretrizes e normas constitucionais tributárias.

Voltando ao FAP, uma leitura atenta da exposição de motivos da MP 83/2002 revela a intenção do Estado de utilizar a majoração da alíquota-base como forma de punição aos contribuintes que mais cometem os ilícitos trabalhistas verificados na empresa. Ainda que a contribuição 
ao SAT tenha como base imponível manifestação de riqueza representada pela folha de pagamento das empresas, resta claro que os demais elementos definidores do tributo não foram devidamente observados.

Tal constatação, nos exatos termos dispostos na classificação de Gouvêa, coloca em xeque a utilização do FAP como tributo extrafiscal, pois ultrapassa os limites objetivos absolutos da fiscalidade. A ausência de preocupação ou investimentos em segurança e saúde do trabalho deveriam gerar multas administrativas, mas nunca adicional de alíquota, na exata e precisa definição de Lobato (2010).

Cabe ainda demonstrar que a imposição de condutas por meio de normas tributárias não pode travestir uma sanção contra o contribuinte sob a forma de tributo, até mesmo pela liberdade de iniciativa definida no artigo 170 da $\mathrm{CF} / 88$. A ordem econômica constitucional designa outras medidas para essa forma de coerção por parte do Estado, não podendo o tributo servir de instrumento sancionador do Estado, que já possui o domínio penal e as sanções administrativas a sua disposição.

A liberdade de iniciativa, inclusive, está disposta nas nossas discussões acerca da aplicação dos limites da ordem constitucional econômica aplicáveis à extrafiscalidade do FAP, conforme se verifica no tópico seguinte.

\subsection{Limites da ordem econômica e demais ramos relevantes}

Chegamos enfim à análise das limitações da extrafiscalidade do FAP ante as diretrizes e normas atinentes ao ramo constitucional que se pretendeu valorizar com a instituição do FAP, na esteira de toda a construção doutrinária citada nos tópicos anteriores. 
Inicialmente, resta claro que um limite lógico à extrafiscalidade do FAP seria o cumprimento da finalidade definida no artigo $7^{\circ}$, inciso $\mathrm{XXVIII}^{7}$ da CF/88, que disciplina o seguro contra acidentes de trabalho como garantia fundamental do trabalhador.

Com efeito, se a contribuição ao SAT pretende efetivar o seguro contra acidentes de trabalho, a cargo do empregador, a norma que estabelece o FAP não poderá, por uma finalidade extrafiscal, desviar a finalidade ou mesmo recursos da contribuição para outros fins desejados pelo Estado. Na exata esteira do pensamento do professor Godoi, a extrafiscalidade não pode pretender violar, ainda que indiretamente, garantias fundamentais do cidadão. Sendo assim, até mesmo pela natureza finalística das contribuições sociais, qualquer desvio causado pela norma extrafiscal seria, em princípio, inconstitucional (Godoi, 2004).

Analisando a estrutura atual da metodologia do FAP, uma crítica concreta que poderia ser feita à sistemática seria a de que a redução das alíquotas básicas, por meio da imposição de FAP menor do que 1 (um), reduziria a extensão do seguro contra acidentes do trabalho, na medida em que limitaria a participação da empresa nesse instituto e diminuiria as fontes de custeio da atividade estatal definida pelo constituinte.

A realidade fática, entretanto, contradiz essa alegação, uma vez que a fórmula paramétrica que fundamenta o FAP, além de não prever queda na receita da contribuição, gera na prática um incremento na arrecadação, à medida que a redução máxima da alíquota-base (de 50\%) não se dá na mesma proporção da majoração permitida (100\% da alíquota base). Da mesma forma, considerando ainda que, normalmente, as maiores e mais organizadas empresas acabam tendo as maiores alíquotas majoradas pelo

7 Artigo $7^{\circ}$ - São direitos dos trabalhadores urbanos e rurais, além de outros que visem à melhoria de sua condição social: [...] XXVIII - seguro contra acidentes de trabalho, a cargo do empregador, sem excluir a indenização a que este está obrigado, quando incorrer em dolo ou culpa (Brasil. Constituição da República Federativa do Brasil de 1988). 
FAP, por conta da alta massa salarial e pelo alto nível de formalização dos eventos trabalhistas, não se nota perda de arrecadação que pudesse fundamentar a alegação de que o FAP reduziria o alcance do SAT. ${ }^{8}$ Esse tipo de análise, em verdade, seria mais exequível quando relacionada à necessária solidariedade do sistema previdenciário, que, conforme discussões definidas no tópico anterior, ligar-se-ia ao ideal de isonomia e universalidade do tributo em si.

Assim, a princípio não há notícias de redução da receita de custeio ao SAT que pudesse justificar a alegação de que o FAP violaria a finalidade social delimitada no inciso XXVIII do artigo $7^{\circ}$ da $\mathrm{CF} / 88$.

Ademais, temos de considerar que a metodologia do FAP, ao visar ao aumento dos investimentos na melhoria das condições do ambiente de trabalho, busca a melhoria da condição social definida pelo constituinte no caput do artigo $7^{\circ}$ da $\mathrm{CF} / 88$, e da mesma forma vislumbra a proteção do trabalhador, que é também buscada por meio do seguro contra acidentes de trabalho.

Assim, em relação à garantia fundamental prevista no artigo $7^{\circ}$ da $\mathrm{CF} / 88$, não se verifica, a princípio, violação pela norma extrafiscal que define o FAP. Caso, entretanto, a prática do sistema demonstre a violação

${ }^{8}$ Essa conclusão é referendada por Lobato, que abalizado por parecer do Conselho Federal de Estatística, atesta o viés de aumento de arrecadação pela instituição do FAP. Vejamos: “Contudo, tal forma de comparação entre as empresas, pela utilização de percentis, acaba por gerar graves distorções, denunciadas em parecer do Conselho Federal de Estatística - Confe - pois tal metodologia (a) privilegia somente a ordenação dos valores, sem considerar a grandeza das acidentalidades, (b) havendo empates na classificação das empresas, as distorções são ainda mais agravadas". E assim conclui o parecer: "Por todo o exposto, dúvidas não remanescem acerca da imprestabilidade do método previsto pelas Resoluções $\mathrm{n}^{\circ}$ 1.308/09 e $\mathrm{n}^{0}$ 1.309/09 para o cálculo do FAP (utilização de percentis), restando inconteste o objetivo arrecadatório na sua eleição; sendo esta, inclusive, uma das conclusões do parecer do Confe, ao afirmar-se que 'o método gera aumento indevido das alíquotas, portanto a metodologia incorpora fatalmente viés de aumento de arrecadação”” (Lobato, 2010). 
a esse direito que o fundamenta, estaremos efetivamente diante de uma prática extrafiscal que extrapola os limites delimitados pela doutrina e pelo constituinte.

Além do capítulo constitucional relativo aos direitos sociais do trabalhador, outros limites à instituição do FAP serão diretrizes da ordem econômica constitucional. Como já disposto, tendo em vista a finalidade precípua da melhoria das condições do ambiente de trabalho, reflexo do fundamento da valorização do trabalho definida no artigo 170 da $\mathrm{CF} / 88,{ }^{9}$ e a existência de intervenção estatal no domínio empresarial com regras que estimulam melhorias no ambiente laboral interno das companhias, fica claro que a extrafiscalidade do FAP também deve passar pelo crivo das limitações impostas pela ordem constitucional econômica.

Volvendo à lição de Schoueri, ao dispor sobre a necessidade de observância dos princípios da ordem econômica, observamos o seguinte:

É no delicado equilíbrio entre segurança jurídica e os princípios da Ordem Econômica, demandando agilidade e versatilidade, que se encontrará o espaço para as cláusulas gerais e para os conceitos indeterminados, enquanto instrumentos de adaptação da própria lei (Schoueri, 2005, p. 321).

Com razão o autor paulista, pois essa necessidade de observância interativa e integrativa entre a competência reguladora da economia e a competência tributária é que dá legitimidade às normas tributárias extrafiscais.

Isso posto, iniciamos a análise do FAP à luz do principal fundamento econômico constitucional para a sua instituição, qual seja, a valorização do trabalho definida no artigo 170 da $\mathrm{CF} / 88$.

9 Brasil. Constituição da República Federativa do Brasil de 1988. 
Evidentemente, estamos diante de um limite jurídico-principiológico de extrafiscalidade, posto que a melhoria das condições de saúde e segurança do ambiente laboral é reflexo direto da valorização do trabalho como gerador de riqueza para o desenvolvimento econômico do Estado.

Não há como negar que a metodologia FAP, ao estimular investimentos por meio de alíquotas minoradas da contribuição SAT, busca promover o princípio constitucional anteriormente citado. Não pode, contudo, na busca desse objetivo, esquecer de outros que integram a ordem econômica nacional, inclusive a função social da propriedade e a liberdade de iniciativa.

O fundamento constitucional da função social da propriedade, que ainda tem seu alcance muito discutido no ordenamento, pressupõe que o agente econômico, no exercício dos direitos sobre o seu patrimônio, deve direcionar sua atuação também ao cumprimento das diretrizes sociais definidas pelo constituinte. Nesse caso, em princípio o FAP parece cumprir esta função social, na medida em que direciona a atividade do empresário ao cumprimento de um objetivo social definido pelo Estado, inclusive cumprindo com o artigo 174 da $\mathrm{CF} / 88$, que outorga ao legislador a competência para estabelecer as bases para o planejamento do desenvolvimento nacional equilibrado. Casso, porém, em algum momento se verifique que o FAP ou a legislação do SAT deixem de privilegiar este aspecto, majorando ou reduzindo injustificadamente as alíquotas flutuantes ou básicas da contribuição (como pareceu ocorrer em relação a algumas atividades elencadas no Decreto 6.957/2009, que alterou os critérios do RAT), evidentemente estaremos em situação que viola os limites de atuação do legislador extrafiscal. 
No nosso entendimento, se a norma tributária extrafiscal torna tão onerosa a atividade que a relega a uma marginalidade quase que ilegal, não estaremos diante de uma figura tributária extrafiscal que promove a justiça social da propriedade, mas sim a uma sanção que acaba por inibir a prática regular de uma atividade lícita.

Trazendo a assertiva anterior ao âmbito do FAP, notamos claramente uma tentativa de punir contribuintes que não realizam investimentos em saúde e segurança no ambiente de trabalho, por meio da imposição de alíquotas maiores que as fixadas por lei. Ao contrário das sanções meramente premiais, nas quais o contribuinte, ciente da alíquota máxima a que é sujeito, realiza investimentos para realizar a finalidade extrafiscal e reduzir sua carga tributária, com o FAP o empresário tem como primeira previsão uma alíquota média, que será majorada caso ele realize o malfeito, ainda que involuntariamente.

Some-se a isso o fato de que o seguro, pela sua própria natureza, se institui para custear indenizações de situações indesejáveis, imprevistas e imprevisíveis, que geram dano ao segurado. No caso específico do SAT, as empresas custeiam o seguro por estarem sujeitas à ocorrência de eventos previdenciários e acidentes laborais causados, frequentemente, pelo risco natural da atividade. A ocorrência desses eventos, na maioria das vezes, não é desejada pela empresa, que não pode ser penalizada por meio de tributação maior do que a normalmente prevista. Na sistemática atual, o empresário é punido com uma alíquota maior do que a por ele esperada na realização normal e lídima de sua atividade econômica (alíquotas básicas definidas pelas alíneas a, b e c do artigo 22, II da lei 8.212/91), Há, em certo grau, uma punição pelo exercício da livre-iniciativa em um ambiente laboral que, para possuir licença de funcionamento, já deve a priori possuir a mínimas condições exigidas em lei. 
Ora, se o contribuinte cumpre com as exigências legais para a abertura e funcionamento de seu negócio, inclusive adotando as medidas legais necessárias para obtenção de alvarás, e além disso contribui para um seguro estatal que cobre riscos normais da atividade, é certo que a tributação adicional e em valor acima do legalmente esperado constitui sanção pelo mero exercício legal da atividade econômica.

Lembramos que não estamos aqui negando o valor nobre da extrafiscalidade do FAP, porém punir o contribuinte aplicando sanções que majoram, sem qualquer previsibilidade, as alíquotas decorrentes do exercício normal da atividade econômica, nos parece desarrazoado e incompatível com a liberdade de iniciativa. Caso haja faltas na conduta do contribuinte, deve a administração instituir os meios adequados para puni-lo pelo descumprimento de suas obrigações, mediante sanções administrativas, civis e penais, mas tomar fato alheio à vontade e inerente ao risco comum como forma de tributação para atingimento de um fim extrafiscal, em nossa percepção não se coaduna com as diretrizes da livre-iniciativa.

\section{CONCLUSÕES}

Diante das discussões anteriormente propostas, acreditamos que avançamos na análise do tema sugerido, expondo as limitações do FAP enquanto norma tributária de caráter extrafiscal.

Entre os achados relevantes do presente estudo, constatamos inicialmente a necessidade de adequar o FAP às diretrizes aplicáveis às ordens constitucionais tributária e econômica, além da necessária correspondência com as garantias fundamentais ao Seguro de Acidente de Trabalho (SAT) definidas pelo constituinte.

Ademais, verificamos que, em relação à ordem tributária, há possíveis inconstitucionalidades e ilegalidades da metodologia FAP ligadas aos limites jurídico-normativos e jurídico-principiológicos da extrafiscali- 
dade, na medida em que a legalidade, a competência formal e material e os princípios da isonomia, da universalidade e da capacidade contributiva parecem estar sendo vilipendiados pelo Estado.

Nesse passo, a adoção de alíquotas delimitadas por meio de decretos, aliadas a uma tentativa de constitucionalizar de forma superveniente a sistemática do FAP podem pôr em xeque a viabilidade do instituto. Da mesma forma, a extrapolação da competência material constitucional para instituição da extrafiscalidade, com a imposição de critérios de distinção não permitidos pelo constituinte, parece ultrapassar os limites extrafiscais da competência material da norma extrafiscal, o que impõe, por consequência, violações à isonomia e à universalidade. Ainda em relação à ordem tributária, demonstramos que a deturpação dos métodos extrafiscais conduz à violação da capacidade contributiva, na medida em que são criados critérios de distinção que não correspondem à efetiva distinção do critério econômico que leva à distinção de alíquotas e bases de cálculo. Por fim, questionamos ainda o fato de a legislação do FAP não seguir a natureza própria dos tributos, impondo obrigações de caráter pecuniário como punição pela prática de atividade indesejada pelo Estado.

Nos demais campos constitucionais, a nosso ver, não agiu com acerto o legislador da sistemática do FAP, posto que parece-nos haver uma patente violação à livre-iniciativa, pela imposição de sanções de natureza tributária por fatos alheios ao previsível exercício lícito da atividade econômica, em um exercício indevido do princípio da função social da propriedade.

\section{REFERÊNCIAS}

BRASIL. Constituição da República Federativa do Brasil de 1988. DF, em 5 out. 1988. Disponível em: <http://www.planalto.gov.br/ccivil_03/constituicao/ constituicao.htm>. Acesso em: $1^{\circ}$ ago. 2015. 
. Código Tributário Nacional. Lei n. 5172, de 25 de outubro de 1966.

Diário Oficial da União, Brasília, DF, 27 out. 1966. Disponível em: <http:// www.planalto.gov.br/ccivil_03/leis/L5172.htm>. Acesso em: $1^{\circ}$ jul. 2015.

. Decreto 6.042, de 12 de fevereiro de 2007. Diário Oficial da União. Brasília, DF, 13 fev. 2007. Disponível em: <http://www.planalto.gov.br/ccivil_03/_ ato2007-2010/2007/decreto/d6042.htm>. Acesso em: 15 jul. 2015.

. Decreto 6.957, de 9 de setembro de 2009. Diário Oficial da União. Brasília, DF, 10 set. 2009. Disponível em: <http://www.planalto.gov.br/ccivil_03/_ ato2007-2010/2009/decreto/d6957.htm>. Acesso em: 15 jul. 2015.

Emenda Constitucional n. 47, de 5 de julho de 2005. DF, em 6. jul. 2005a. Disponível em: <http://www.planalto.gov.br/ccivil_03/Constituicao/ Emendas/Emc/emc47.htm> Acesso em: $1^{\circ}$ ago. 2015.

. Lei ordinária 8.212 de 24 de julho de 1991. Diário Oficial da União. Brasília, DF, 24 jul. 1991a. Disponível em: <http://www.planalto.gov.br/ ccivil_03/leis/L8212cons.htm>. Acesso em: 15 jul. 2015.

. Lei ordinária 8.213 de 24 de julho de 1991. Diário Oficial da União. Brasília, DF, 24 jul. 1991b. Disponível em: <http://www.planalto.gov.br/ CCIVIL_03/leis/L8213cons.htm>. Acesso em: 15 jul. 2015.

. Lei ordinária 10.666 de 8 de maio de 2003. Diário Oficial da União. Brasília, DF, 8 maio 2003a. Disponível em: <http://www.planalto.gov.br/ ccivil_03/leis/2003/L10.666.htm>. Acesso em: 15 jul. 2015.

. Medida Provisória $N^{o}$ 83, de 12 de dezembro de 2002. Diário Oficial da União, Brasília, DF, 13 dez. 2002. Disponível em: <http://www.planalto.gov. br/ccivil_03/mpv/Antigas_2002/83.htm>. Acesso em: 15 jul. 2015.

. Supremo Tribunal Federal - STF. Recurso Extraordinário 343.446/ $R S$. Relator Ministro Carlos Velloso. DF, 4 de abril de 2003b. Disponível em: $<\mathrm{http}$ ://www.stf.jus.br/portal/diarioJustica/verDiarioProcesso.asp?numDj=65 \&dataPublicacaoDj $=04 / 04 / 2003 \&$ incidente $=2013286 \&$ codCapitulo $=5 \&$ numM ateria $=9 \&$ codMateria=1 $>$. Acesso em: 30. jun. 2015, p. 1.404-1.405. 
. Supremo Tribunal Federal - STF. Recurso Extraordinário 346.084/PR.

Relator Ministro Ilmar Galvão. DF, 9 de novembro de 2005b. Disponível em: $<\mathrm{http}$ ://www.stf.jus.br/portal/jurisprudencia/listarJurisprudencia.asp?s1=\%2 8RE\%24\%2ESCLA\%2E+E+346084\%2ENUME\%2E\%29+OU+\%28RE\%2EACMS\%2 $\mathrm{E}+\mathrm{ADJ} 2+346084 \% 2 \mathrm{EACMS} \% 2 \mathrm{E} \% 29 \&$ base=baseAcordaos\&url=http://tinyurl. com/b83jq44> Acesso em: 15 de ago. 2015.

DERZI, Misabel Abreu Machado. Modificações da jurisprudência: proteção da confiança, boa-fé objetiva e irretroatividade como limitadores constitucionais ao poder judicial de tributar. São Paulo: Noeses, 2009.

GODOI, Marciano Seabra. Extrafiscalidad y sus limites constitucionales. Revista Internacional de Direito Tributário da Associação Brasileira de Direito Tributário. Belo Horizonte: Ed. Del Rei, v. 1, n. 1, p. 219-262, 2004.

GOUVÊA, Marcus de Freitas. A extrafiscalidade no direito tributário. Belo Horizonte: Del Rey, 2006.

LEÃO, Martha Toribio. Critérios para o controle das normas tributárias indutoras: uma análise pautada no princípio da igualdade e na importância dos efeitos. 2014. Dissertação (Mestrado) - Universidade de São Paulo, USP, Programa de Pós-Graduação em Direito, São Paulo, 2014. p. 42.

LOBATO, Valter de Souza. O Custeio da Seguridade Social e os benefícios de risco. Os princípios aplicáveis e os limites ao poder de tributar. In: DERZI, Misabel de Abreu Machado (Org.). Separação de poderes e efetividade do sistema tributário. 1. ed. São Paulo: Del Rey, 2010. p. 431-453. V. 1. Disponível em: <http://sachacalmon.com.br/wp-content/uploads/2010/12/Artigo-FAPSATRAT-Valter-Lobato.pdf $>$. Acesso em: 2 ago. 2015.

- O princípio da confiança retratado no Código Tributário Nacional. A aplicação dos artigos 100 e 146 do CTN. A análise de casos concretos. Revista Brasileira de Direito Tributário e Finanças Públicas, v. 6, p. 42-70, 2012. Disponível em: <http://sachacalmon.com.br/wp-content/uploads/2012/09/ArtigoMisabel-analise-dos-arts-100-e-146-do-CTN-final.pdf s. Acesso em: 2 ago. 2015. 
MOSCHETTI, Francesco. El principio de capacidade contributiva. Tradução Juan M. Calero Gallego e Rafael Navas Vasquez. Madrid: Instituto de Estudos Fiscales, 1980.

NABAIS, José Casalta. O dever fundamental de pagar impostos: contributo para a compreensão do estado fiscal contemporâneo. Coimbra: Livraria Almedina, 1988.

PIMENTA, D. M. FAP: questões polêmicas. Disponivel em: <http://jus.com. br/artigos/41410/fap-questoes-polemicas >. Acesso em: 31 jul. 2015.

SILVA, José Afonso da. Curso de Direito Constitucional Positivo. 19. ed. São Paulo: Malheiros, 2001.

SCHOUERI, Luis Eduardo. Normas tributárias indutoras e intervenção econômica. Rio de Janeiro: Forense, 2005.

Recebido em: 23/3/2016

Aceito em: 25/4/2016 